\title{
Acupuncture plus Low-Frequency Electrical Stimulation (Acu-LFES) Attenuates Diabetic Myopathy by Enhancing Muscle Regeneration
}

\author{
Zhen Su, ${ }^{1,3}$, Alayna Robinson ${ }^{3}$, Li Hu${ }^{2,3}$, Janet D. Klein ${ }^{3}$, Faten Hassounah ${ }^{3}$, Min $\mathrm{Li}^{3}$, \\ Haidong Wang ${ }^{3}$, Hui Cai ${ }^{3}$, Xiaonan H. Wang ${ }^{3 *}$ \\ 1 Department of Nephrology, The First Affiliated Hospital of Wenzhou Medical University, Wenzhou, \\ Zhejiang, China, 2 Acumox and Tuina Research Section, College of Acumox and Tuina, Shanghai University \\ of Traditional Chinese Medicine, Shanghai, China, 3 Renal Division, Department of Medicine, Emory \\ University, Atlanta, GA, United States of America \\ *xwang03@emory.edu
}

\section{Gopenaccess}

Citation: Su Z, Robinson A, Hu L, Klein JD, Hassounah F, Li M, et al. (2015) Acupuncture plus Low-Frequency Electrical Stimulation (Acu-LFES) Attenuates Diabetic Myopathy by Enhancing Muscle Regeneration. PLOS ONE 10(7): e0134511. doi:10.1371/journal.pone.0134511

Editor: Ashok Kumar, University of Louisville School of Medicine, UNITED STATES

Received: April 4, 2015

Accepted: July 9, 2015

Published: July 31, 2015

Copyright: @ 2015 Su et al. This is an open access article distributed under the terms of the Creative Commons Attribution License, which permits unrestricted use, distribution, and reproduction in any medium, provided the original author and source are credited.

Data Availability Statement: All relevant data are within the paper.

Funding: NIAMS R01 AR060268 to XW (PI), National Natural Science Foundation of China (30871179) to ZS (PI), and Zhejiang Provincial Program for the Cultivation of High-level Innovative Health Talents to ZS (PI).

Competing Interests: The authors have declared that no competing interests exist.

\section{Abstract}

Mortality and morbidity are increased in patients with muscle atrophy resulting from catabolic diseases such as diabetes. At present there is no pharmacological treatment that successfully reverses muscle wasting from catabolic conditions. We hypothesized that acupuncture plus low frequency electric stimulation (Acu-LFES) would mimic the impact of exercise and prevent diabetes-induced muscle loss. Streptozotocin (STZ) was used to induce diabetes in mice. The mice were then treated with Acu-LFES for 15 minutes daily for 14 days. Acupuncture points were selected according to the WHO Standard Acupuncture Nomenclature guide. The needles were connected to an SDZ-II electronic acupuncture device delivering pulses at $20 \mathrm{~Hz}$ and $1 \mathrm{~mA}$. Acu-LFES prevented soleus and EDL muscle weight loss and increased hind-limb muscle grip function in diabetic mice. Muscle regeneration capacity was significantly increased by Acu-LFES. The expression of Pax7, MyoD, myogenin and embryo myosin heavy chain $(\mathrm{eMyHC})$ was significantly decreased in diabetic muscle vs. control muscle. The suppressed levels in diabetic muscle were reversed by AcuLFES. The IGF-1 signaling pathway was also upregulated by Acu-LFES. Phosphorylation of Akt, mTOR and p70S6K were downregulated by diabetes leading to a decline in muscle mass, however, Acu-LFES countered the diabetes-induced decline. In addition, microRNA1 and -206 were increased by Acu-LFES after 24 days of treatment. We conclude that AcuLFES is effective in counteracting diabetes-induced skeletal muscle atrophy by increasing IGF-1 and its stimulation of muscle regeneration. 


\section{Introduction}

Muscle wasting is an independent index for mortality and morbidity in catabolic conditions [1, 2], such as diabetes, chronic kidney disease, heart failure, cancer, sepsis, burn injury, AIDS and denervation [3-6]. Muscle loss is mainly reflective of increased myofibrillar protein breakdown [7]. Loss of muscle protein results in muscle atrophy and weakness. These have significant clinical consequences, up to and including decreased life expectancy. Therefore, effective therapeutic strategies to treat muscle wasting induced by catabolic diseases are needed.

The prevalence of diabetes worldwide is increasing [8]. Diabetes affects more than ten million Americans. The routine injection of insulin before meals has substantially improved the lives of people who suffer from diabetes by controlling their hyperglycemia, but this does not address the other aspects of diabetes. There is an overall failure of this treatment to eliminate the development of long-term complications that result from insulin resistance. We have evidence that insulin resistance and/or insulin deficiency will cause muscle weakness in diabetes $[4,9,10]$. This clinical condition is termed diabetic myopathy, which is a reduction in skeletal muscle size and strength [11]. Diabetic myopathy is a significant, but often overlooked, complication that contributes an overall worsening of the diabetic condition. Maintenance of healthy muscle capacity is of vital importance for our physical and metabolic well-being. In addition to locomotion, skeletal muscle constitutes about $40 \%$ of our body mass and is a major metabolic organ system. A key challenge in diabetes is to maintain muscle mass which requires muscle regeneration.

Muscle regeneration is a multistep process [12]. The first step is to activate myogenic stem cells, also known as satellite cells. Pax7 is a transcription factor that activates satellite cells leading to initial myogenesis [13]. After initiation, the muscle cells can either proliferate or return to quiescence. MyoD is a marker of myogenic commitment to muscle proliferation and differentiation. Following differentiation, the cells need to fuse either with new or previously existing fibers during the process of differentiation. Myogenin is required for the fusion of myogenic precursor cells. At this point the muscle has regenerated to a mature form that is capable of contraction. Myosin comprises a family of ATP-dependent motor proteins and is best known for their role in muscle contraction. They are responsible for actin-based motility. Myosin heavy chain protein is a marker indicating mature muscle. Together, these markers give a comprehensive picture of the muscle regeneration status in either healthy or diabetic animals.

Previously we and others discovered that exercise has the ability to prevent a decrease of skeletal muscle mass [5]. Unfortunately, patients with severe diseases are frequently unable to consistently exercise. Although substantial efforts have been made to understand and treat muscle wasting, pharmacologic treatments for muscle wasting have had limited success. Acupuncture is a branch of traditional Chinese medicine that is widely applied to treat various diseases. Acupuncture plus Low-frequency electrical stimulation (Acu-LFES) is an acupuncture technique that replicates the benefits of exercise through stimulation of muscle contraction. Our previous studies found that Acu-LFES is a non-pharmacologic approach that can prevent muscle loss induced by chronic kidney disease [14].

In this study, we investigated the impact of Acu-LFES on diabetic myopathy. We believe that regardless of the underlying cause or catabolic condition, there are common mechanisms that are part of the muscle wasting process. One such commonality is a decrease in insulin-like growth factor 1 (IGF-1) signaling that leads to muscle wasting. We hypothesized that AcuLFES would upregulate the IGF-1 signaling pathway, resulting in suppressed diabetes-induced muscle loss. We report here that Acu-LFES improves muscle health by influencing muscle regeneration in diabetes. The positive effects of Acu-LFES could provide an additional therapeutic option for treatment of diabetic myopathy. 


\section{Materials and Methods}

\section{Animals and diabetic model}

Mice (C57BL/6J, 8-10 weeks, male) were housed in the animal care facility in 12-h light, 12-h dark cycles and fed ad libitum with normal chow. The experiments were approved by the institutional animal care and use committee (IACUC) of Emory University. Streptozotocin (STZ) induction of diabetes and Acu-LFES were described in detail in the Complete Research Description section of approved IACUC Protocol number: DAR-2002853. Mice were randomly assigned into four groups: control, Acu-LFES, diabetes and diabetes/Acu-LFES ( $\mathrm{n}=12$ / group). Diabetes was induced by STZ injection [10, 15]. STZ-Na-Citrate solution was freshly prepared immediately prior to injection. Mice were injected with STZ in citrate buffer (1.47 g

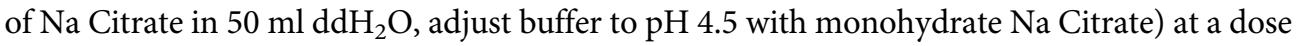
of $150 \mathrm{mg} / \mathrm{kg}$ mouse. The final concentration of STZ in the Na-Citrate buffer was $22.5 \mathrm{mg} / \mathrm{ml}$. Each mouse received injections on two consecutive days. Blood glucose was measured by Accu-Chek Aviva Plus Test Strips (Roche Diagnostics, Indianapolis, IN). At the end of the experiment, mice were euthanatized by cervical dislocation. The gastrocnemius, soleus and extensor digitorum longus (EDL) muscles were removed, muscle weights were measured and then muscles were immersed in liquid nitrogen and stored at $-80^{\circ} \mathrm{C}$ for further experiments. The muscles were analyzed for mRNA and protein in a combined sample because this more accurately reflects the comprehensive muscle response to the acupuncture treatment.

\section{Muscle grip function}

Grip strength was measured using a mouse grip strength meter with dual computerized sensors to detect and record the grip force (Columbus Instruments, Columbus, $\mathrm{OH}$ ). Mice were allowed to grip a grid connected to a force transducer and gently pulled by the tail for 5 seconds. The computerized sensors determine what force was needed to counter-balance the grip of the mice. Mice were tested before the STZ injection and Acu-LFES treatment and 14 days after Acu-LFES just before harvesting the muscle. The grip strength of each mouse was tested 5 times on each testing occasion, with 10 minutes rest between each test. The average of the 5 determinations was reported.

\section{Acu-LFES treatment}

The mice were kept in specially designed restraint so that they would remain in a recumbent position during Acu-LFES treatment. Acupuncture points were selected according to the WHO Standard Acupuncture guidelines [16]. The positive point (Yang Ling Quan, GB34) is in the hollow of the exterior-inferior of the caput fibulae about $6 \mathrm{~mm}$ deep. This position is close to the superficial fibular nerve and deep fibular nerve. The negative point ( $\mathrm{Zu} \mathrm{San} \mathrm{Li,} \mathrm{ST36)} \mathrm{is} 5$ $\mathrm{mm}$ beneath the capitulum fibulae and located laterally and posterior to the knee-joint about 7 $\mathrm{mm}$ deep and close to fibular nerve. The needles were connected to an SDZ-II Electronic acupuncture instrument using consistent pulse, electric frequency $20 \mathrm{~Hz}$, electric current $1 \mathrm{~mA}$. The Acu-LFES was administered for 15 minutes every day for 14 days. Disposable sterile needles with a diameter of $0.25 \mathrm{~mm}$ (Shen Li Medical \& Health Material Co., Ltd., Wujiang, China) were used.

\section{Western blot and antibodies}

Hind limb muscles were homogenized in RIPA Buffer. Proteins were subjected to Western blot analysis using previously published methods [9]. Primary antibodies included: Akt/p-Akt (Ser473), FoxO1/p-FoxO1 (Thr32), mTOR/p-mTOR (Ser2448), 70S6K/p-p70S6K (Thr389) 
were purchased from Cell Signaling (Danvers, MA). MyoD, Pax7, Myogenin, eMyHC are from DSHB product (University of Iowa, lowa City, IA). GAPDH is from Millipore (Burlington, MA). Antibodies were used at a 1:1000 dilution except where indicated. Protein bands were scanned and quantified using the Li-cor Odyssey infrared scanning system (Li-COR Biosciences, Lincoln, NE).

\section{Muscle Immunohistology}

The method for immunohistology of muscle cross sections has been previously described [10]. Muscles were embedded in TBS Tissue Freezing Media (Fisher, Pittsburgh, PA) in isopentane cooled in dry ice. Muscle cross sectional slices $(10 \mathrm{~mm})$ were mounted on gelatin-coated slides were fixed in $4 \%$ paraformaldehyde for $10 \mathrm{~min}$. Tissue was permeabilized in $0.05 \%$ Triton X100 (in PBS) for $10 \mathrm{~min}$, and quench-fixed in $50 \mathrm{mM} \mathrm{NH}_{4} \mathrm{Cl}$ for another $10 \mathrm{~min}$. Samples were blocked with $5 \%$ bovine serum albumin for $1 \mathrm{~h}$, followed by incubation overnight with polyclonal anti-laminin antibody (Sigma-Aldrich). Sections were further incubated for 60 min with FITC donkey anti-rabbit IgG (Jackson Immuno Research Lab, West Grove, PA). Nuclei were stained with DAPI. Images were visualized with an Olympus 1X51 inverted fluorescence microscope and captured by DP73-1-51-17MP color camera. The muscle fiber cross sectional area for each muscle was an average of at least 500 individual myofibers, measured using the cellSens Dimension 1.9 Software (Olympus, Melville, NY). The size of the myofibers reported reflects an average from six mice per group.

\section{Quantitative measurement of mouse IGF-1 in muscle lysate}

IGF-1 Mouse Enzyme-Linked Immunosorbent Assay (ELISA) Kit (ab100695) was purchased from Abcam (Cambridge, MA) and used according to manufacturer's instructions.

\section{Reverse transcription and quantitative polymerase chain reaction (q- PCR) for mRNA and microRNA}

Total RNA was extracted using Tri-Reagent (Molecular Research Inc., Cincinnati, OH). RNA was subjected to reverse transcription and qPCR using previously published methods [17]. For microRNA, the miRCURY LNA Universal cDNA Synthesis kit (Exiqon Inc., Woburn, MA) was used for reverse transcription of microRNA. The primers were custom designed by Exiqon. The miRCURY LNA microRNA PCR SYBR Green master mix (Exiqon INC) was used for qPCR with the following cycle parameters: $95^{\circ} \mathrm{C}$ for 10 minutes and 45 cycles at $95^{\circ} \mathrm{C}$ for 10 seconds and $60^{\circ} \mathrm{C}$ for 60 seconds. Expression of individual miRNA was normalized to the mouse U6 gene and calculated as the difference between the threshold values of the two genes $(\Delta \Delta \mathrm{cq})$.

\section{Conventional Reverse transcription PCR (RT-PCR) for mRNA}

Total RNA from mouse muscle was isolated using Tri-Reagent. Reverse transcription was performed using the M-MLV reverse transcriptase (Life Technologies, Grand Island, NY) and $2 \mu \mathrm{g}$ denatured RNA according to the manufacturer's instructions. Primers for specific genes were designed to cross intron-exon boundaries and used to generate amplicons in their linear ranges. For each sample, $18 \mathrm{~S}$ rRNA was used as an internal control. The following primers were used for RT-PCR: MyoD (M84918), forward 5' - GCC CGC GCT CCA ACT GCT CTG AT $-3^{\prime}$, reverse $5^{\prime}$ - CCT ACG GTG GTG CGC CCT CTG C - $3^{\prime}$ (amplicon 397 nt); Pax-7 (NM_01039), forward 5' - TGG AAG TGT CCA CCC CTC TTG GC $-3^{\prime}$, reverse $5^{\prime}-$ ATC CAG ACG GTT CCC TTT GTC GCC -3' (amplicon $510 \mathrm{nt}$ ); eMyHC (M11154), forward 5' - GAA 
GAA GAA CCT GGA GCA GAC G - 3' , reverse 5' - AGC CTG CCT CTT GTA GGA CTT G-3' (amplicon $301 \mathrm{nt}$ ) and Myogenin (NM_031189), forward 5' - TGC ACT CCC TTA CGT CCA TCG T-3' ${ }^{\prime}$, reverse 5' - AGG TCA GGG CAC TCA TGT CTC T-3' (amplicon 454 nt).

\section{Statistical analysis}

Data are presented as mean \pm se. To identify significant differences between two groups, comparisons were made using a Student's t-test. For a comparison of more than two groups, ANOVA was performed with a post hoc analysis by the Student-Newman-Keuls test. Differences with $\mathrm{P}$ values $<0.05$ were considered significant.

\section{Results}

\section{Acu-LFES prevents diabetes-induced muscle wasting and improves muscle function}

In diabetic mice, blood glucose values were three times higher than those of control mice $(P<0.01)$. The weights of soleus (slow-contracting dark type I fiber) and EDL (fast-twitch white type II fiber) muscles in mice with diabetes were significantly less than those of control mice, but those of non-diabetic mice treated with Acu-LFES were not significantly different from those of control mice (Table 1). However, the muscle weights were significantly higher in diabetic mice with Acu-LFES than in diabetic mice without Acu-LFES. The muscle function of the mice, as measured by the grip strength meter, is shown in Table 2. There was no significant difference in muscle function between non-diabetic mice with and those without Acu-LFES. Diabetic mice had lower grip function than did control mice, but diabetic mice treated with Acu-LFES had higher muscle grip capacity than did diabetic mice without Acu-LFES (diabetes: $3.8 \pm 0.9 \mathrm{KGF}^{-2}$; diabetes/Acu-LFES: $\left.5.2 \pm 1.0 \mathrm{KGF}^{-2} ; P<0.05\right)$.

\section{Acu-LFES prevents diabetes-induced muscle fiber cross-sectional area decrease}

Muscle fiber cross-sectional area was determined in frozen sections of EDL muscles using an anti-laminin antibody. The size of muscle fibers was significantly smaller in diabetic mice without Acu-LFES than in diabetic mice with Acu-LFES. Fiber area frequency distribution revealed a clear increase in the percentage of small fibers (a leftward shift) in diabetic mice (Fig 1). AcuLFES in diabetic mice suppressed the leftward shift in the fiber size distribution.

\section{Acu-LFES improves muscle regeneration in normal and diabetic mice}

To study how Acu-LFES prevents muscle wasting in diabetic mice, we first measured the mRNA of myogenesis markers. In the muscles of diabetic mice, the mRNA expressions of $P A X 7$ (transcription factor to initial myogenesis), MYOD (proliferation marker), myogenin (differentiation marker), and $\mathrm{e} M y \mathrm{HC}$ (embryo myosin heavy chain differentiation and fusion marker) were significantly lower than those of control mice (Fig 2). Acu-LFES reversed the diabetes-induced suppression of myogenesis mRNA. The protein levels of muscle regeneration markers also provide evidence that Acu-LFES stimulates muscle regeneration capacity in both healthy and diabetic mice (Fig 3). All myogenesis markers tested were increased by Acu-LFES in healthy controls: by 1.9-fold for PAX7, 4.1-fold for MYOD, 2.1-fold for myogenin, and 4.3-fold for eMyHC. The PAX7, MYOD, and eMyHC markers were significantly decreased in muscles of diabetic mice; Acu-LFES reversed these decreases. Myogenin protein was also decreased in the muscles of diabetic mice, but the change was not statistically significant. However, among diabetic mice, myogenin was significantly higher in those treated with Acu-LFES 
Table 1. Muscle and body Weights.

\begin{tabular}{lcccc}
\hline & control & Acu-LFES & Diabetes & Diabetes/Acu-LFES \\
\hline Body weight (g) & $24.9 \pm 2.9$ & $24.1 \pm 2.6$ & $21.3 \pm 1.9$ & $23.2 \pm 2.6$ \\
Soleus (mg) & $11.1 \pm 2.0$ & $11.8 \pm 1.7$ & $8.3 \pm 1.5^{*}$ & $10.0 \pm 1.7^{\#}$ \\
EDL (mg) & $10.8 \pm 1.3$ & $11.0 \pm 1.6$ & $8.4 \pm 2.0^{*}$ & $9.9 \pm 1.5^{\#}$ \\
gastrocnemius (mg) & $140.4 \pm 9.3$ & $145.0 \pm 11.9$ & $118.4 \pm 12.8^{*}$ & $138.9 \pm 11.3^{\#}$ \\
soleus/body (x100) & $44.2 \pm 3.9$ & $48.9 \pm 4.1$ & $39.0 \pm 3.2^{*}$ & $43.4 \pm 5.2^{*}$ \\
EDL/body (x100) & $43.4 \pm 2.4$ & $45.6 \pm 1.2$ & $553.9 \pm 9.7$ & $42.7 \pm 4.7^{\#}$ \\
Gastrocnemius/body (x100) & $563.9 \pm 8.2$ & $601.7 \pm 7.6$ & $303.2 \pm 5.3^{*}$ & $594.8 \pm 8.3$ \\
Blood glucose (mg \%) & $100.3 \pm 6.1$ & $102.2 \pm 5.3$ & & $289.3 \pm 16.7^{*}$ \\
\hline
\end{tabular}

Data are presented as mean \pm s.e.;

$P<0.05$ is significant ( ${ }^{*} v s$. control, ${ }^{*} v s$. Diabetes), $n=12 /$ group.

doi:10.1371/journal.pone.0134511.t001

than in those not treated with Acu-LFES. These results show that Acu-LFES prevents diabetesinduced muscle wasting by stimulating muscle regeneration.

Myofibers containing central nuclei indicate muscle regeneration. Under normal control conditions, satellite cells, also known as muscle stem cells, are generally located at the periphery of the myofibers. Upon initiation of myogenesis by Acu-LFES, satellite cells migrate into the myofibers (Fig 4). We found that central nuclei are apparent in muscles of both diabetic and non-diabetic mice treated with Acu-LEFS. However, the percentage increase in central nuclei was higher in the muscles of diabetic/Acu-LFES than of non-diabetic/Acu-LFES mice. These results indicate that Acu-LFES prevents muscle atrophy partly by stimulating myogenesis.

\section{Acu-LFES upregulates protein synthesis-related proteins in diabetic mice}

Building muscle mass requires an increase in protein synthesis as well as the activation of myogenesis signaling. We tested protein synthesis-related proteins in all groups of mice (Fig 5). Both the phosphorylation of the mammalian target of rapamycin (p-mTOR) and the phosphorylation of the p70S6 kinase (p-p70S6) were significantly decreased in diabetic mice. The p-mTOR was increased 1.5-fold in muscles of non-diabetic mice treated with Acu-LFES over those of control mice; it was increased 1.6-fold in muscles of diabetic mice treated with AcuLFES over those of diabetic mice that were not treated with Acu-LFES. The p-p70S6, which is downstream from mTOR in the protein synthesis pathway, was increased 2.0-fold in AcuLFES-treated non-diabetic mice and 2.3-fold in Acu-LFES-treated diabetic mice over that of diabetic mice without Acu-LFES treatment. These results demonstrate that Acu-LFES

Table 2. Muscle function was increased by LFES.

\begin{tabular}{lcl}
\hline & Before Acu-LFES $\left(\right.$ KGF $\left.^{-2}\right)$ & After Acu-LFES $\left(\right.$ KGF $\left.^{-2}\right)$ \\
\hline Control & $4.9 \pm 0.2$ & $5.1 \pm 0.6$ \\
Acu-LFES & $4.7 \pm 0.6$ & $6.6 \pm 0.8$ \\
Diabetes & $5.0 \pm 0.4$ & $3.8 \pm 0.9^{*}$ \\
Diabetes/Acu-LFES & $4.8 \pm 0.4$ & $5.2 \pm 1.0^{\#}$ \\
\hline
\end{tabular}

$P<0.05$ is significant ( ${ }^{*} v s$. control, ${ }^{*}$ Vs. diabetes), $n=12 /$ group.

$\mathrm{KGF}^{-2}$, kilogram-force/100; Data are presented as mean \pm s.e.;

doi:10.1371/journal.pone.0134511.t002 


\section{(A)}
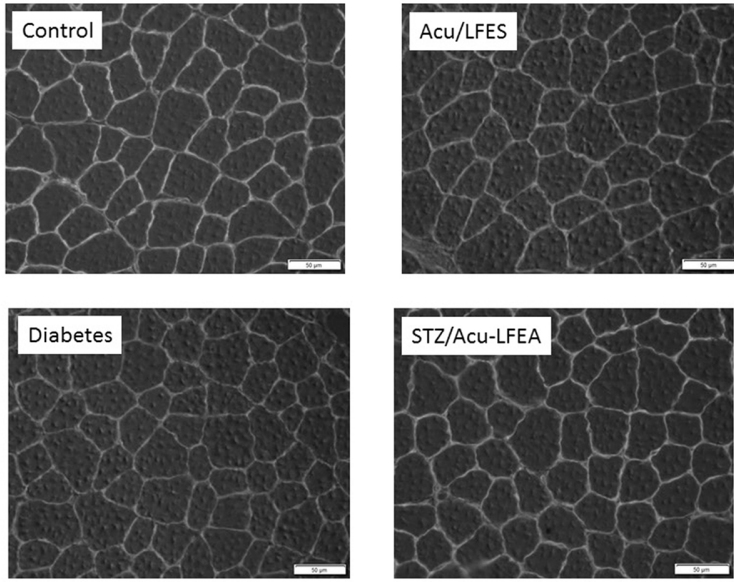

(B)

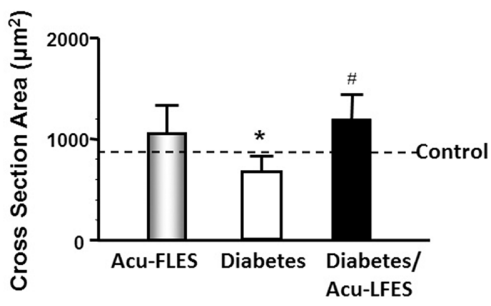

(C)

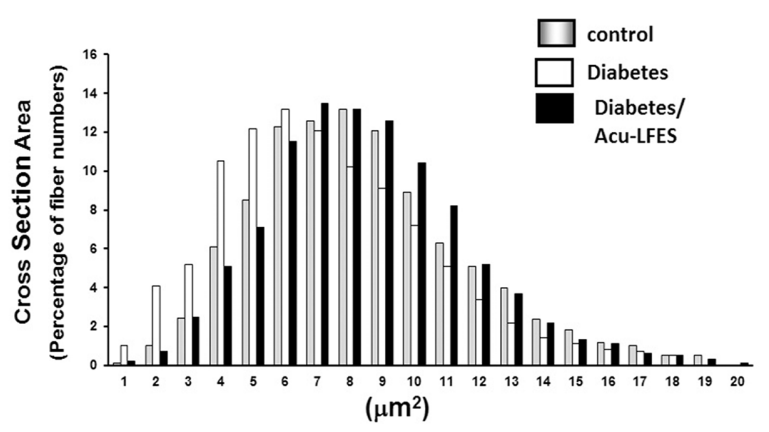

Fig 1. Acu-LFES prevents diabetes-induced muscle fiber cross-sectional area (MCS) decrease. A representative cross-sectional area of EDL muscle from normal control (control), Acu-LFES treated normal controls (Acu-LFES), diabetes or diabetes/Acu-LFES mice are showed (A). The cryosections of EDL muscle were immunostained with anti-laminin antibody. The First bar graph (B) shows the average size of myofibers

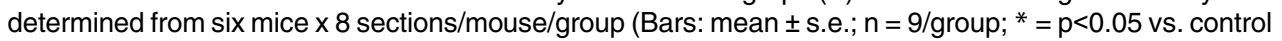
and $\#=p<0.05 \mathrm{vs}$. diabetes). The frequency distribution of fiber cross-sectional area in control (grey bar), diabetes (open bar) and diabetes/Acu-LFES (black bar) mice is presented as percent fibers/size of fibers (C). doi:10.1371/journal.pone.0134511.g001 

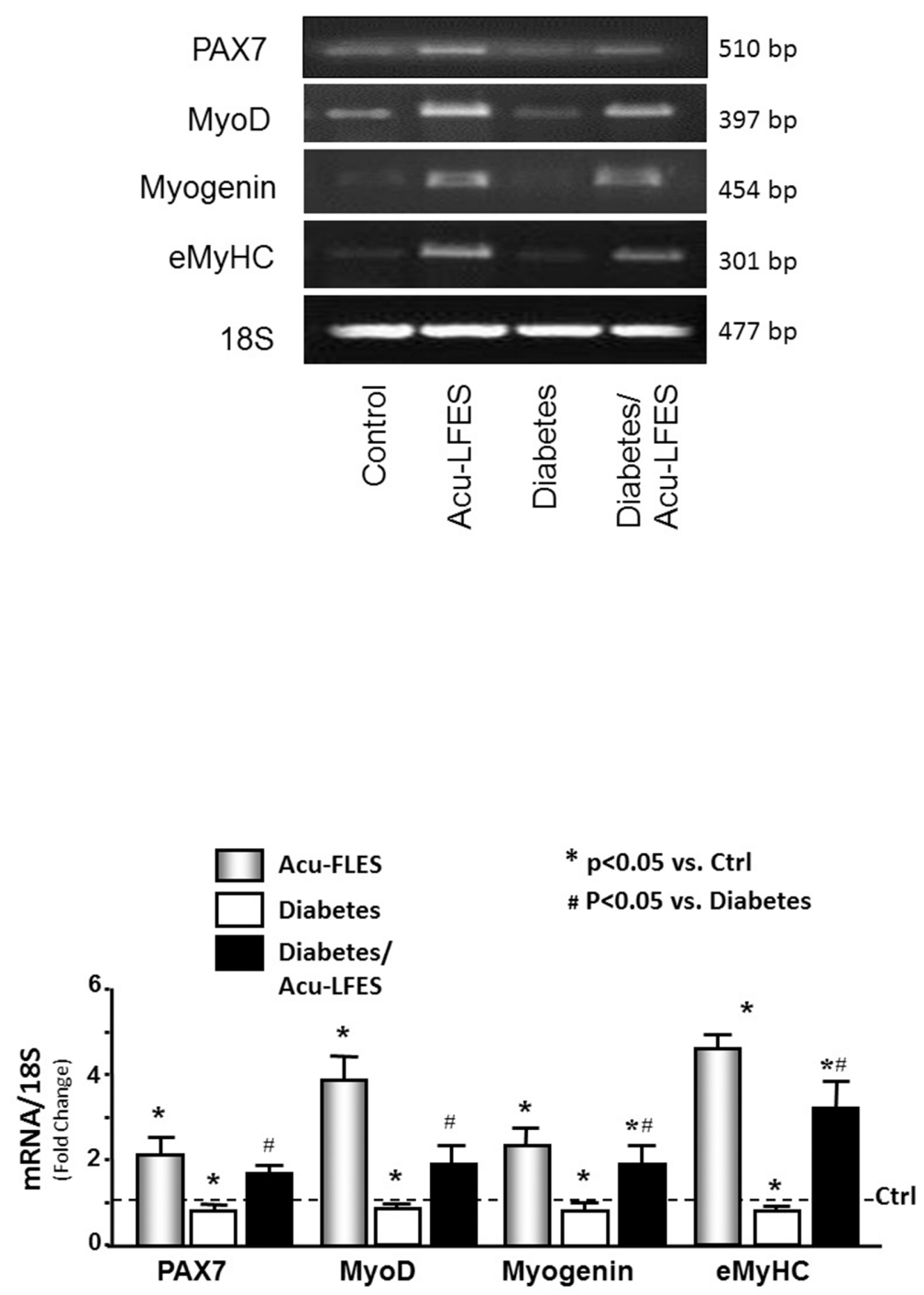

Fig 2. Acu-LFES increases muscle regeneration of mRNA markers. $\mathrm{Pax} 7$, myoD, myogenin and eMyHC were measured by conventional RT-PCR in combined gastrocnemius and EDL muscle lysates from control, Acu-LFES, diabetes or diabetes/Acu-LFES mice. The bar graph compares the densities of mRNA bands in each group expressed as a fold-change from levels in control mice which is represented by a line at 1 -fold. All band densities were normalized to the density of the 18 S rRNA band (Bars: mean \pm s.e.; $n=12 /$ group; * $p<0.05$ vs. control and $\#=p<0.05$ vs. diabetes).

doi:10.1371/journal.pone.0134511.g002

counteracts the diabetes-induced decrease in the phosphorylation of mTOR or p70S6, thereby potentially increasing protein synthesis.

\section{Acu-LFES increases Akt phosphorylation in diabetic mice}

Phosphorylation of Akt is important for muscle growth. Phosphorylation of FoxO is critical for prohibiting pro-catabolic functions of FoxO [18]. We assayed phosphorylation of these two proteins in all groups of mice (Fig 6). The phosphorylation of Akt was increased 1.6-fold in control muscle and 2.0-fold in diabetic muscle by Acu-LFES treatment over those of diabetic mice that were not treated with Acu-LFES. The Thr32 phosphorylation of FoxO1 was increased 1.9-fold in Acu-LFES-treated non-diabetic mice and 1.8-fold in Acu-LFES-treated 

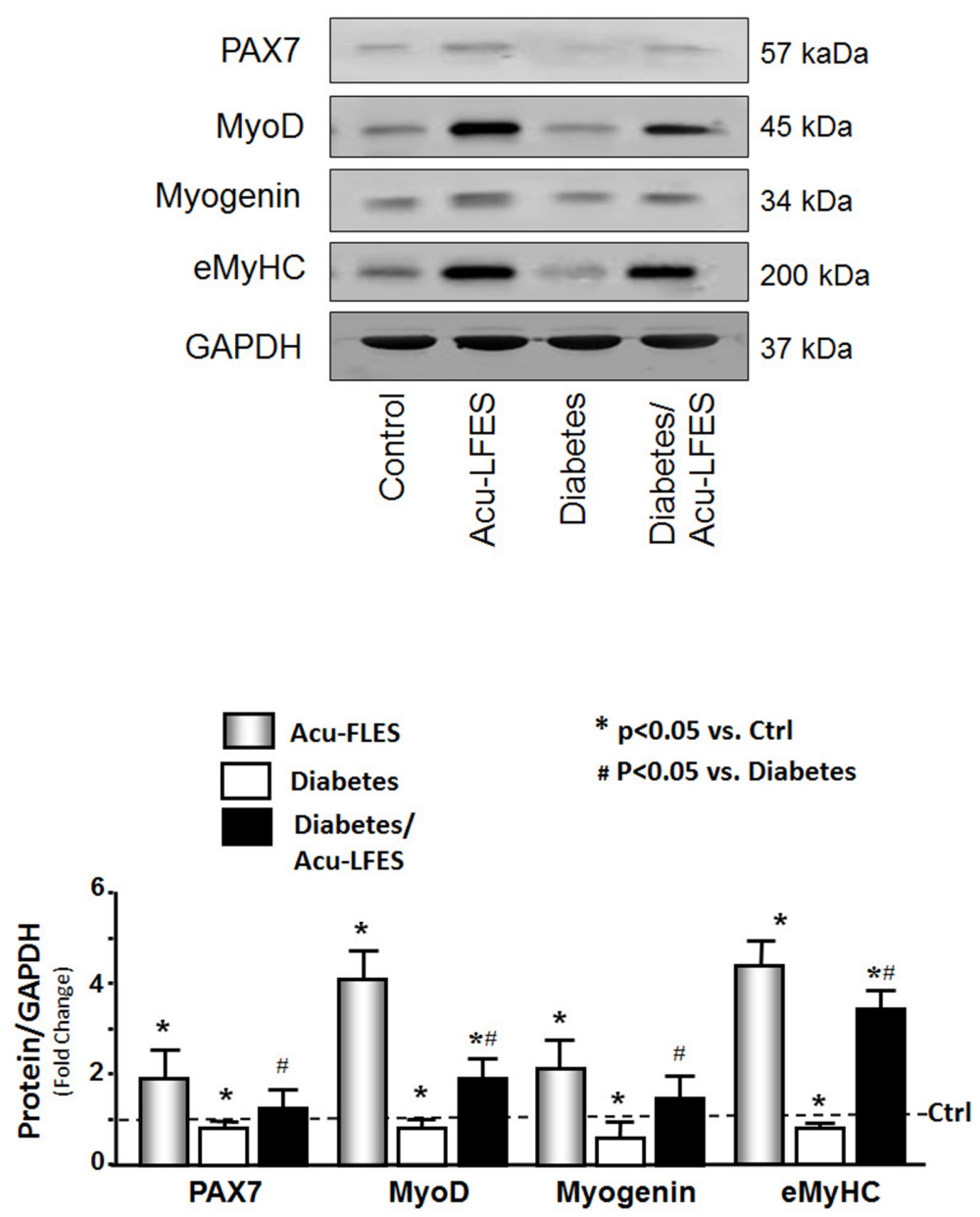

Fig 3. Acu-LFES counteracts diabetes-induced decrease of muscle regeneration proteins. Muscle proteins lysates were prepared from combined gastrocnemius and EDL muscles from control, Acu-LFES, diabetes or diabetes/Acu-LFES mice. Muscle regeneration related proteins ( $\mathrm{Pax} 7, \mathrm{myoD}$, myogenin, eMyHC) and GAPDH were measured by western blotting. The bar graph compares the protein band densities in each treatment group expressed as a fold-change from levels in control mice (represented by a line at 1-fold). All band densities were normalized to the density of GAPDH (Bars: mean \pm s.e.; $n=12 /$ group; ${ }^{*}=p<0.05$ vs. control and $\#=p<0.05$ vs. diabetes).

doi:10.1371/journal.pone.0134511.g003

diabetic mice over that of diabetic mice not treated with Acu-LFES. These results demonstrate that Acu-LFES improves protein synthesis by increasing AKT and FoxO1 phosphorylation.

\section{Acu-LFES upregulates the IGF-1 signaling pathway in skeletal muscle of normal and diabetic mice}

To investigate how Acu-LFES increases muscle mass and activates the muscle regeneration process, we identified the mRNA expression of IGF-1 using quantitative real-time PCR (qPCR). Acu-LFES increased IGF-1 expression 2.0-fold in non-diabetic mice. IGF-1 expression was $16 \%$ lower in diabetic mice than in non-diabetic mice. However, Acu-LFES reversed this trend; IGF-1 expression was increased 1.8-fold in diabetic mice treated with Acu-LFES over that of diabetic mice not treated with Acu-LFES (Fig 7). Protein levels of IGF-1 were measured by enzyme-linked immunosorbent assay in muscle lysates. IGF levels were $20 \%$ lower in 

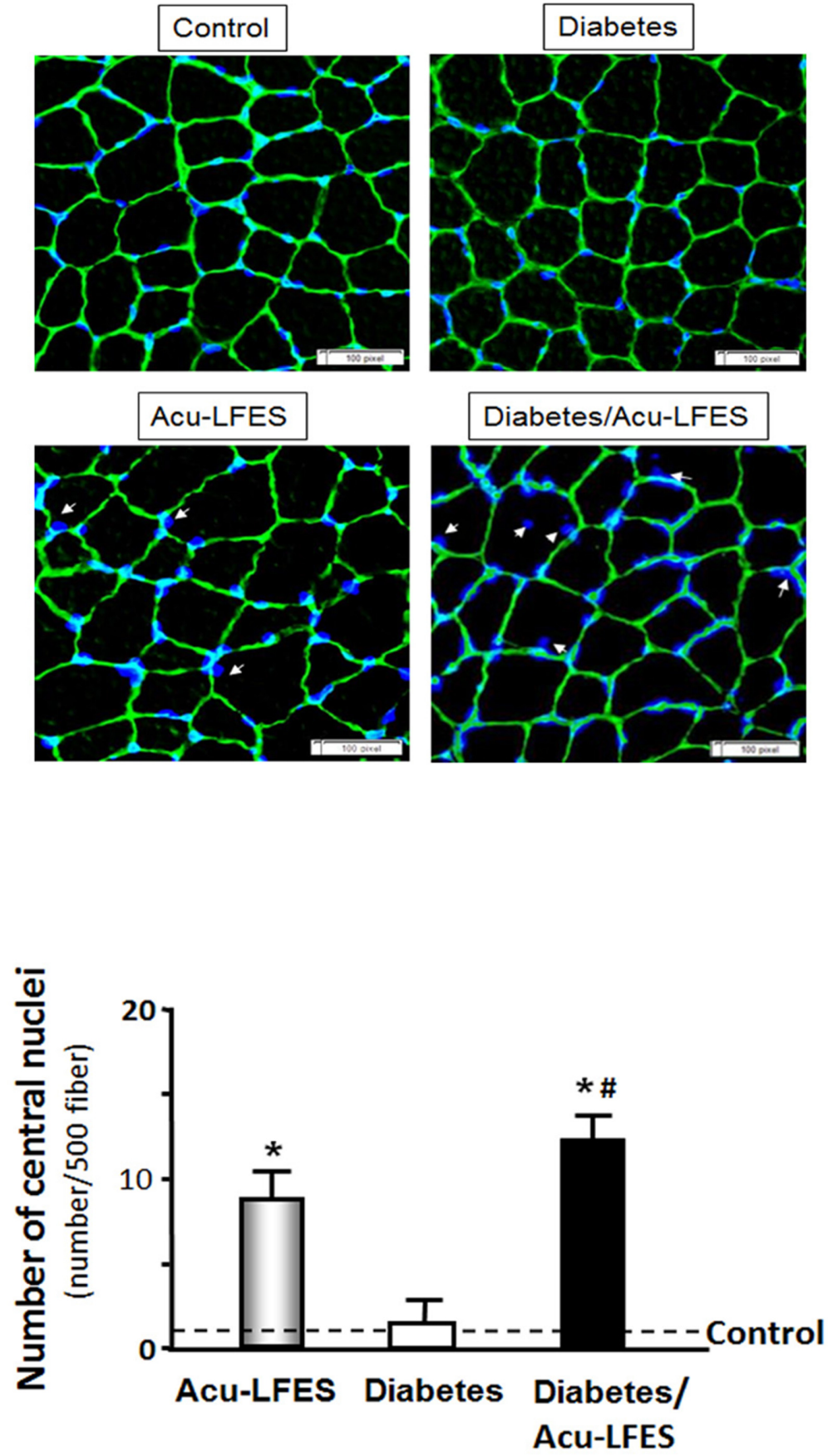

Fig 4. Acu-LFES increase satellite cells migration in normal and diabetic mice. A representative crosssections from EDL muscles after staining for laminin (green) and counterstaining with DAPI (blue) are shown in control, Acu-LFES, diabetes or diabetes/Acu-LFES mice. The white arrows point to central nuclei inside of myofibers which indicates satellite cells migration. The bar graph shows the nuclei number inside (central nuclei) per 500 muscle fibers (Bars: mean \pm s.e.; $n=9$; $\#=p<0.05$ vs. control)

doi:10.1371/journal.pone.0134511.g004 

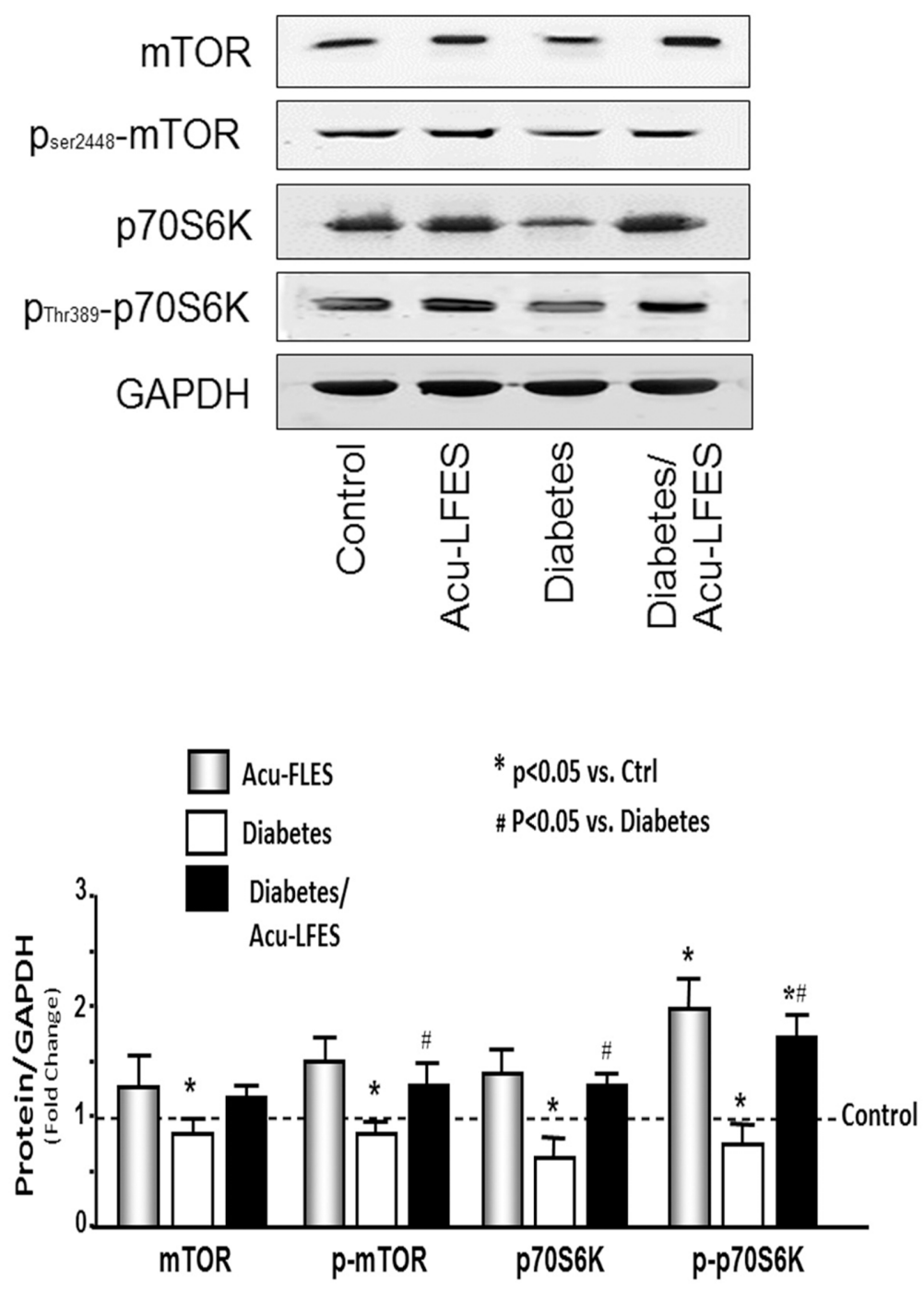

Fig 5. Acu-LFES improves protein synthesis markers in skeletal muscle of diabetic mice. The protein synthesis related markers mTOR, p-mTOR, p70S6K and p-p70S6K were measured by western blotting in combined gastrocnemius and EDL muscle lysates from control, Acu-LFES, diabetes or diabetes/Acu-LFES mice. The bar graph compares the densities of protein bands in each group expressed as a fold-change from levels in control mice which is represented by a line at 1 -fold. All band densities were normalized to the density of GAPDH (Bars: mean \pm s.e.; $n=12 /$ group; * $=p<0.05$ vs. control and $\#=p<0.05$ vs. diabetes).

doi:10.1371/journal.pone.0134511.g005

diabetic mice than in control mice. Acu-LFES increased IGF-1 protein 1.9-fold in the muscles of diabetic mice indicating that IGF-1 is increased by Acu-LFES treatment in mice.

\section{Acu-LFES enhances the expression of microRNAs (myomiRs)}

Muscle regeneration is also regulated by myomiRs. To determine whether Acu-LFES stimulates the expression of muscle-specific microRNAs, we measured microRNAs by qPCR in muscle after 14 days of Acu-LFES (Fig 8). The expressions of miR1 and miR206 were significantly decreased in diabetic mice but were increased by Acu-LFES in non-diabetic mice (2.5-fold for miR1 and 2.7 fold for miR206) and diabetic mice (2.0-fold for miR1 and 1.8-fold for miR206). The expressions of both miR133a and miR133b in control mice were increased 1.3-fold by 

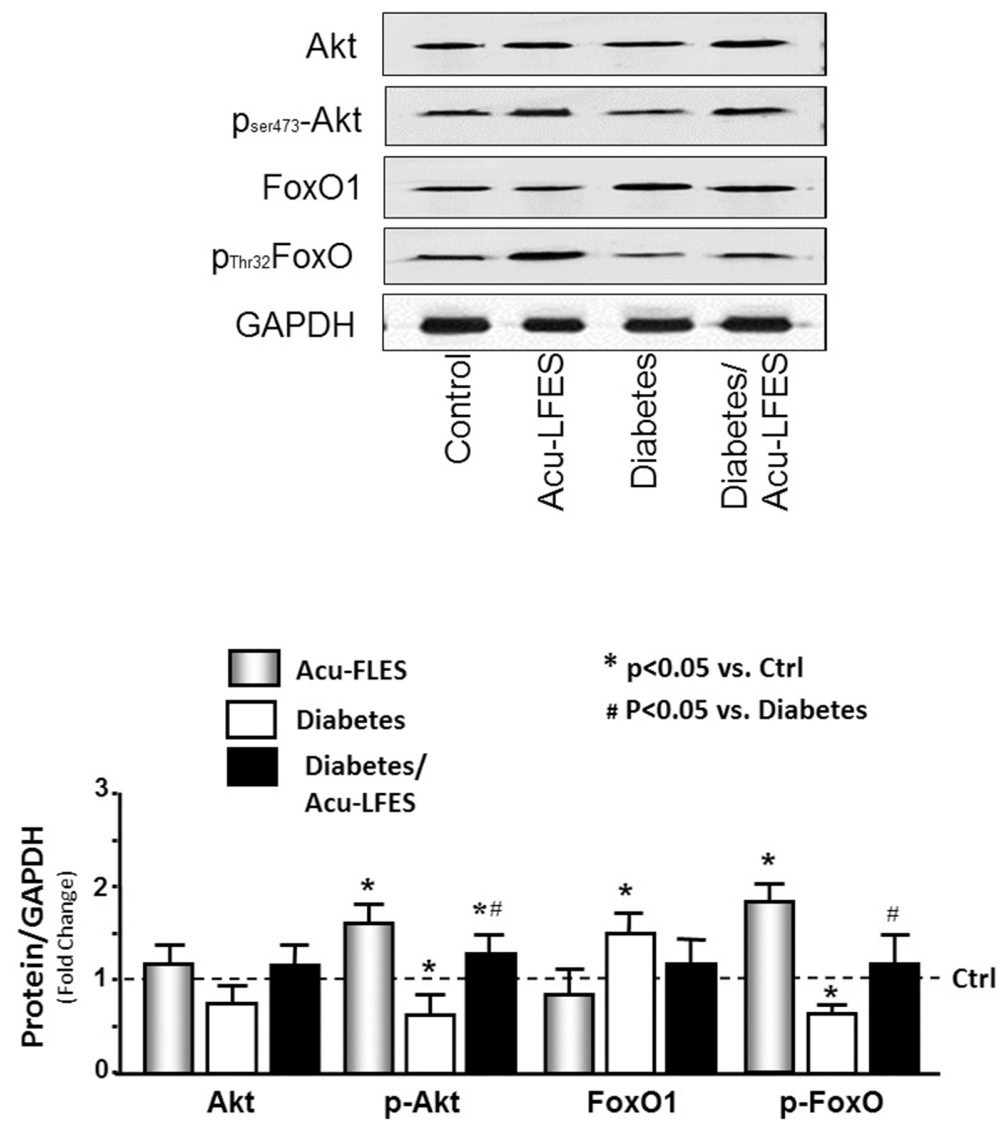

Fig 6. Acu-LFES improve Akt phosphorylation and inhibit FoxO activation in the muscle of diabetic mice. The protein metabolism related proteins Akt, p-Akt, FoxO1 and p-FoxO1 were measured by western blotting in combined gastrocnemius and EDL muscle lysates from control, Acu-LFES, diabetes or diabetes/ Acu-LFES mice. The bar graph compares the densities of protein bands in each group expressed as a foldchange from levels in control mice which is represented by a line at 1 -fold. All band densities were normalized to the density of GAPDH (Bars: mean \pm s.e.; $n=12 /$ group; ${ }^{*}=p<0.05$ vs. control and $\#=p<0.05$ vs. diabetes).

doi:10.1371/journal.pone.0134511.g006

Acu-LFES, but the change was not statistically significant. However, Acu-LFES significantly increased miR133a and b expression in diabetic mice (1.5-fold for miR133a and 1.7-fold for miR133b). These data indicate that one of the methods by which Acu-LFES promotes muscle regeneration is the stimulation of myomiR expression.

\section{Discussion}

The mechanisms that cause muscle protein loss in catabolic disease have been widely studied. Identification of common pathways of muscle wasting should lead to therapeutic strategies that are beneficial for all catabolic conditions. Other researchers and we have found that decrease of IGF-1 is a common pathway for muscle wasting, and upregulation of the IGF-1 signaling pathway counteracts muscle atrophy in diabetes and chronic renal failure in animal models $[4,5,9,19,20]$. In this study, we identified a simple non-pharmacologic treatment, Acu-LFES, which is able to increase IGF-1 signaling and prevent diabetes-induced muscle atrophy by stimulating muscle regeneration.

Much effort has been made to identify new therapeutic approaches to preventing muscle wasting. Pharmacologic treatments for muscle atrophy that have been studied in animal 


\section{(A)}
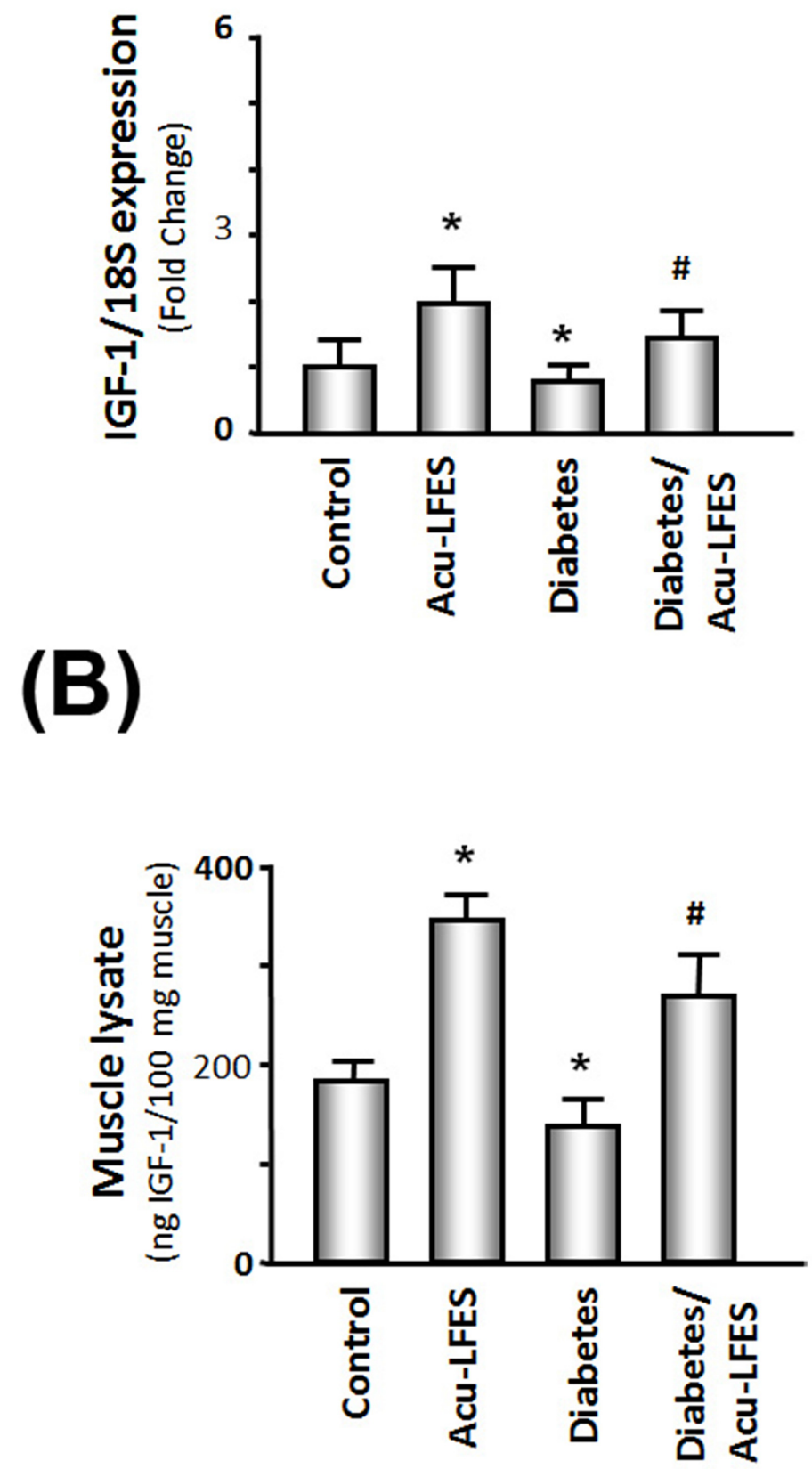

Fig 7. Acu-LFES upregulates IGF-1 mRNA and protein in the muscle of diabetic mice. Panel A: Total RNA isolated from combined gastrocnemius and EDL muscles of control, Acu-LFES, diabetes or diabetes/ Acu-LFES mice were assayed for IGF-1 expression by real time qPCR. The bar graph shows mRNA from the

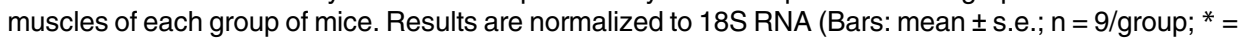
$p<0.05$ vs. control and $\#=p<0.05$ vs. diabetes). Panel $B$ : IGF-1 protein levels were measured by ELISA in in combined gastrocnemius and EDL lysates from control, Acu-LFES treated normal controls (Acu-LFES), diabetes or diabetes/Acu-LFES mice. The bar graph shows the IGF-1 protein levels in each group. IGF-1 levels in the muscle lysates were normalized to the total protein concentration (Bars: mean \pm s.e.; $n=9$; * $p<0.05$ vs. control and $\#=p<0.05$ vs. diabetes)

doi:10.1371/journal.pone.0134511.g007 
(A)

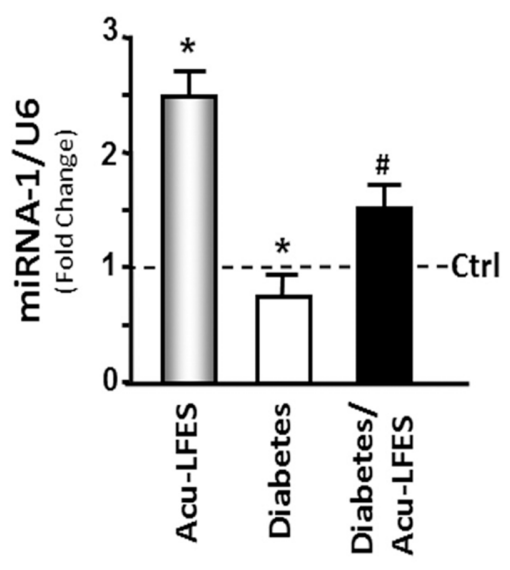

(B)

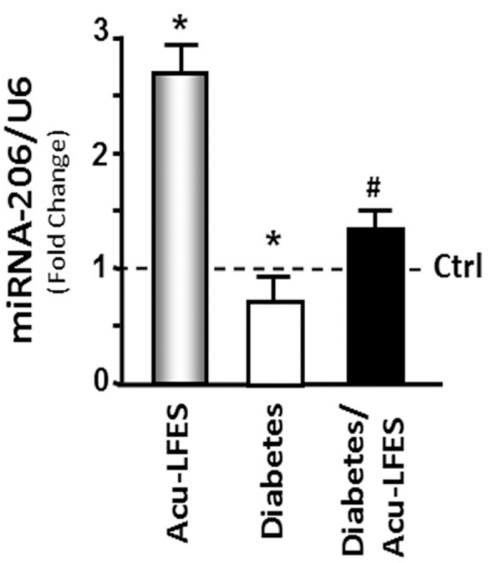

* $\mathrm{p}<0.05$ vs. Ctrl

\# $\mathrm{P}<0.05$ vs. Diabetes

(C)

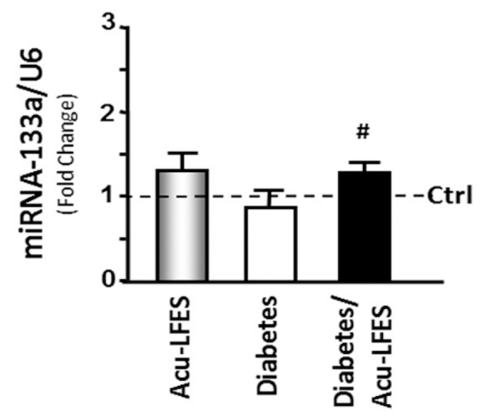

(D)

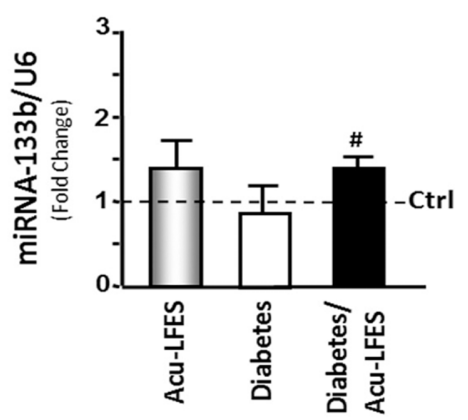

Fig 8. Acu-LFES increase miR-1 and miR-206 microRNA in the muscle of control and diabetic mice. Total RNA was isolated from combined gastrocnemius and EDL muscles of control, Acu-LFES, diabetes or diabetes/Acu-LFES, and then assayed for specific microRNA expression. miR-1 (A), miR-206 (B), miR-133a (C) and miR-133b (D) expressions were measured using real time qPCR with LNA-enhanced oligonucleotide primers. The bar graph shows microRNA levels in each group expressed as a fold-change from levels in control mice which is represented by a line at 1 -fold. All band densities were normalized to the density of U6 RNA (Bars: mean \pm s.e.; $n=6 /$ group; ${ }^{*}=p<0.05$ vs. control and $\#=p<0.05$ vs. diabetes).

doi:10.1371/journal.pone.0134511.g008

models and clinical trials include an anti-myostatin peptibody [21]; Stat3 inhibitor [22]; anabolic androgenic steroids such as nandrolone decanoate, a synthetic derivative of testosterone [23]; IGF-1 and its analogues [24]; an angiotensin-II receptor antagonist, losartan [25]; proteasome inhibitors [26, 27]; MURF1 inhibitor PO13222 [28]; a caspase inhibitor called X-linked inhibitor of apoptosis protein [3, 10]; and antisense oligonucleotides [29]. However, pharmacologic treatments have adverse effects, and no simple and efficient treatments are currently in clinical use. Non-pharmacologic therapy, such as exercise, upregulates the IGF-1 signaling pathway and decreases myostatin in muscle tissue of animals [5,30] and humans [31,32], thus preventing muscle atrophy. Unfortunately, patients with severe disease are usually unable to exercise consistently. Therapies that can safely suppress muscle wasting in patients who are bedridden or in wheelchairs are needed. 
Therapeutic acupuncture is widely used in the United States and around the world [33]. According to the National Institutes of Health Consensus Development Panel on acupuncture, the evidence of acupuncture's value is sufficient to expand its use into conventional medicine [33]. In a British Acupuncture Council survey, no serious adverse events were reported after 34,407 acupuncture treatments, proving that acupuncture is a safe non-pharmacologic treatment $[34,35]$. Acupuncture and Acu-LFES can decrease skeletal muscle atrophy induced by hind limb suspension in mice [36]. Electrical acupuncture treatment has been shown to suppress myostatin expression, which leads to satellite cell proliferation and skeletal muscle repair [37]. Previously, we performed Acu-LFES on mice with muscle atrophy induced by chronic kidney disease and found that Acu-LFES treatment improves muscle weight and function [14].

In the current study, we determined that Acu-LFES slows muscle wasting in diabetic mice by promoting muscle regeneration. Skeletal muscle is a postmitotic tissue. Mature muscles are composed of muscle fibers surrounded by a basal lamina that covers myofibrils and muscle precursor cells (satellite cells) [20,38]. Satellite cells underneath the lamina are generally quiescent. However, in response to muscle injury or changes in growth factors (e.g., IGF-1), they begin to express myogenic regulatory factors (MYOD, Myf5, myogenin, and MRF4), leading to satellite cell proliferation, differentiation, and fusion to form myofibrils. In this way, myofibrils are repaired or enlarged. MYOD is one of the earliest markers of myogenic commitment and is also expressed in adult muscle in a muscle-specific manner. The influence of catabolic disease on the function of satellite cells has received limited attention. In a previous study, we provided evidence that satellite cell function is impaired by catabolic disease [20]. In the current study, we found that Acu-LFES promotes muscle regeneration and increases PAX7, which activates satellite cells and increases MYOD, myogenin, and eMyHC. This could promote satellite cell proliferation and differentiation.

The beneficial effects of Acu-LFES on muscle regeneration may be achieved by two mechanisms: upregulating IGF-1 or increasing muscle-specific microRNA (myomiR).

In this study, the gastrocnemius and EDL muscles were used together in the Western blot and PCR analyses. The gastrocnemius muscle was chosen because it is the major muscle in the distal hind limb. The EDL muscle was chosen because the two acupuncture points (positive: Yang Ling Quan, GB34; negative: Zu San Li, ST36) are very close to the EDL. The muscles were analyzed in a combined sample because this more accurately reflects the comprehensive muscle response to acupuncture treatment. We believe that LFES produces a nerve-borne effect that affects both muscles together. We found that Acu-LFES improves muscle regeneration by reversing the diabetes-induced suppression of IGF-1, p-Akt (protein anabolic markers), and pmTOR (protein synthesis markers). Our results and those of other investigators have shown that IGF-1 plays a central role in controlling the muscle wasting of diabetes and other catabolic disease $[4,9,18]$. In general, an increase in IGF-1 signaling will counteract muscle atrophy induced by muscle injury and disease $[4,5,9,19,20]$. In the current study, we found that AcuLFES upregulates IGF-1 mRNA, and protein. An increase in IGF-1 inhibits activation of the protein catabolic marker FOXO by increasing FOXO phosphorylation, thus providing a means of increasing muscle mass and function. An increase in IGF-1 will initiate muscle regeneration and protein synthesis and lead to increased muscle mass and function.

Acu-LFES appears to have the greatest effect on pre-existing muscle atrophy. Our results showed that muscle size is not induced in control with Acu-LFES-treated mice, despite the increases in IGF-1 and genes associated with regeneration proteins. The number of central nuclei was significantly higher in diabetic mice treated with Acu-LFES than in non-diabetic mice treated with Acu-LFES (Fig 4). Further study is required to explain this difference.

Several studies have revealed that microRNA is involved in the regulation of muscle regeneration [39]. MicroRNAs that are expressed mainly, but not exclusively, in muscle and that 
have significant impact on myogenesis are called myomiRs [39]. MyomiRs include miR1, -133, -206 , -208 , and -499 . In a rat skeletal muscle injury model, injection of double-stranded miR1, miR133, and miR206 into muscle induced MYOD, PAX7, and myogenin, leading to increased muscle regeneration [40]. One study provided evidence that miR1 and miR206 directly target PAX3, leading to initiation of the myogenic program [41]. A recent study demonstrated that miR1 and miR206 play a major role in myoblast differentiation by regulating multiple target genes [42]. Evidence that miR206 promotes skeletal muscle regeneration is found both in mice with normal muscles and in those with Duchenne muscular dystrophy [43]. In the current study, we found that miR1 and -206 were decreased in the muscle tissue of diabetic mice. AcuLFES not only increased miR1 and -206 in muscles of normal mice but also prevented the decrease of myomiRs in muscles of diabetic mice.

The benefits of acupuncture to diabetic animals and humans may extend beyond increasing muscle regeneration. In a randomized, controlled clinical trial, Man et al. found that electroacupuncture improves insulin sensitivity [44]. Their study used electric acupuncture at bilateral ST36 and SP6 acupoints in 52 female patients and found that acupuncture was associated with prevention of hyperglycemia because of increased insulin sensitivity. The improvement of insulin sensitivity has been confirmed by other studies [45].

As with any treatment, acupuncture should be used with proper precautions. In the course of our studies, we have found that acupuncture has advantages and disadvantages. This may be the reason that previous acupuncture studies have sometimes shown equivocal results [46]. We found that Acu-LFES can activate macrophages and cause an acute pro-inflammatory response [14]. This pro-inflammatory response could promote myogenesis; however, long-term inflammation could also cause muscle damage. The timing and intensity of Acu-LFES seem to be strongly associated with the degree of inflammatory response. The long-term benefits or adverse effects of Acu-LFES were not established in this study.

Our study has some limitations. First, this study does not distinguish between the effects of acupuncture and electrical stimulation. It is possible that acupuncture actually induces damage and that LFES induces the increase in muscle size. Second, the effect on muscle mass of upregulation of miR1 and miR206 by Acu-LFES should be studied further. MyomiRs may increase signal differentiation during embryogenesis, but other studies have shown that overexpression of miR1 and miR206 inhibits IGF-1 expression [47]. In the current study, we found that IGF-1 signaling actually increased.

In conclusion, Acu-LFES ameliorated diabetes-induced skeletal muscle atrophy by improving muscle regeneration, leading to increased muscle mass and function. The increased muscle regeneration capacity is due to upregulation of the IGF-1 signaling pathway and an increase in the expression of myomiRs.

\section{Author Contributions}

Conceived and designed the experiments: ZS LH XHW. Performed the experiments: ZS AR LH FH ML HW. Analyzed the data: ZS AR LH FH HC JK XHW. Contributed reagents/materials/analysis tools: ZS JK XHW ML. Wrote the paper: ZS HC JK XHW.

\section{References}

1. Griffiths RD. Muscle mass, survival, and the elderly ICU patient. Nutrition. 1996; 12(6):456-8. PMID: 8875547.

2. Windsor JA, Hill GL. Risk factors for postoperative pneumonia. The importance of protein depletion. Ann Surg. 1988; 208(2):209-14. PMID: 3401064. 
3. Hu J, Du J, Zhang L, Price SR, Klein JD, Wang XH. XIAP reduces muscle proteolysis induced by CKD. J Am Soc Nephrol. 2010; 21(7):1174-83. Epub 2010/05/01. doi: 10.1681/ASN.2009101011 PMID: 20431038; PubMed Central PMCID: PMC3152227.

4. Wang X, Hu Z, Hu J, Du J, Mitch WE. Insulin resistance accelerates muscle protein degradation: Activation of the ubiquitin-proteasome pathway by defects in muscle cell signaling. Endocrinology. 2006; 147(9):4160-8. Epub 2006/06/17. doi: 10.1210/en.2006-0251 PMID: 16777975.

5. Wang XH, Du J, Klein JD, Bailey JL, Mitch WE. Exercise ameliorates chronic kidney disease-induced defects in muscle protein metabolism and progenitor cell function. Kidney Int. 2009; 76(7):751-9. Epub 2009/07/31. doi: 10.1038/ki.2009.260 PMID: 19641484.

6. Song YH, Li Y, Du J, Mitch WE, Rosenthal N, Delafontaine P. Muscle-specific expression of IGF-1 blocks angiotensin II-induced skeletal muscle wasting. J Clin Invest. 2005; 115(2):451-8. Epub 2005/ 01/15. doi: 10.1172/JCI22324 PMID: 15650772; PubMed Central PMCID: PMC544037.

7. Wang $\mathrm{XH}$, Mitch WE. Mechanisms of muscle wasting in chronic kidney disease. Nature reviews Nephrology. 2014; 10(9):504-16. Epub 2014/07/02. doi: 10.1038/nrneph.2014.112 PMID: 24981816.

8. Lam DW, LeRoith D. The worldwide diabetes epidemic. Current opinion in endocrinology, diabetes, and obesity. 2012; 19(2):93-6. Epub 2012/01/21. PMID: 22262000.

9. Zhou Q, Du J, Hu Z, Walsh K, Wang XH. Evidence for adipose-muscle cross talk: opposing regulation of muscle proteolysis by adiponectin and Fatty acids. Endocrinology. 2007; 148(12):5696-705. Epub 2007/09/01. doi: 10.1210/en.2007-0183 PMID: 17761767.

10. Wang $\mathrm{XH}, \mathrm{Hu}$ J, Du J, Klein JD. X-chromosome linked inhibitor of apoptosis protein inhibits muscle proteolysis in insulin-deficient mice. Gene Ther. 2007; 14(9):711-20. Epub 2007/02/23. doi: 10.1038/sj.gt. 3302927 PMID: 17315041; PubMed Central PMCID: PMC3786557.

11. D'Souza DM, Al-Sajee D, Hawke TJ. Diabetic myopathy: impact of diabetes mellitus on skeletal muscle progenitor cells. Frontiers in physiology. 2013; 4:379. Epub 2014/01/07. doi: 10.3389/fphys.2013. 00379 PMID: 24391596; PubMed Central PMCID: PMC3868943.

12. Ten Broek RW, Grefte S, Von den Hoff JW. Regulatory factors and cell populations involved in skeletal muscle regeneration. J Cell Physiol. 2010; 224(1):7-16. Epub 2010/03/17. doi: 10.1002/jcp.22127 PMID: 20232319.

13. Brack AS, Rando TA. Tissue-specific stem cells: lessons from the skeletal muscle satellite cell. Cell Stem Cell. 2012; 10(5):504-14. Epub 2012/05/09. doi: 10.1016/j.stem.2012.04.001 PMID: 22560074; PubMed Central PMCID: PMC3348769.

14. Hu L, Klein JD, Hassounah F, Cai H, Zhang C, Xu P, et al. Low-Frequency Electrical Stimulation Attenuates Muscle Atrophy in CKD-A Potential Treatment Strategy. J Am Soc Nephrol. 2014. Epub 2014/09/ 18. doi: 10.1681/ASN.2014020144 PMID: 25228359.

15. Hu J, Klein JD, Du J, Wang XH. Cardiac muscle protein catabolism in diabetes mellitus: activation of the ubiquitin-proteasome system by insulin deficiency. Endocrinology. 2008; 149(11):5384-90. Epub 2008/07/26. doi: 10.1210/en.2008-0132 PMID: 18653708; PubMed Central PMCID: PMC2734490.

16. Lim S. WHO Standard Acupuncture Point Locations. Evidence-based complementary and alternative medicine: eCAM. 2010; 7(2):167-8. Epub 2009/02/11. doi: 10.1093/ecam/nep006 PMID: 19204011; PubMed Central PMCID: PMC2862941.

17. Hu Z, Klein JD, Mitch WE, Zhang L, Martinez I, Wang XH. MicroRNA-29 induces cellular senescence in aging muscle through multiple signaling pathways. Aging (Albany NY). 2014; 6(3):160-75. Epub 2014/ 03/25. PMID: 24659628; PubMed Central PMCID: PMC4012934.

18. Wang $\mathrm{XH}$, Mitch WE. Muscle wasting from kidney failure-a model for catabolic conditions. Int J Biochem Cell Biol. 2013; 45(10):2230-8. Epub 2013/07/23. doi: 10.1016/j.biocel.2013.06.027 PMID: 23872437.

19. Lee SW, Dai G, Hu Z, Wang X, Du J, Mitch WE. Regulation of muscle protein degradation: coordinated control of apoptotic and ubiquitin-proteasome systems by phosphatidylinositol 3 kinase. J Am Soc Nephrol. 2004; 15(6):1537-45. Epub 2004/05/22. PMID: 15153564.

20. Zhang L, Wang $\mathrm{XH}$, Wang $\mathrm{H}$, Du J, Mitch WE. Satellite cell dysfunction and impaired IGF-1 signaling cause CKD-induced muscle atrophy. J Am Soc Nephrol. 2010; 21(3):419-27. Epub 2010/01/09. doi: 10.1681/ASN.2009060571 PMID: 20056750; PubMed Central PMCID: PMC2831855.

21. Zhang L, Rajan V, Lin E, Hu Z, Han HQ, Zhou X, et al. Pharmacological inhibition of myostatin suppresses systemic inflammation and muscle atrophy in mice with chronic kidney disease. Faseb J. 2011; 25(5):1653-63. Epub 2011/02/02. doi: 10.1096/fj.10-176917 PMID: 21282204; PubMed Central PMCID: PMC3079306.

22. Zhang L, Pan J, Dong Y, Tweardy DJ, Garibotto G, Mitch WE. Stat 3 activation links a C/EBPdelta to myostatin pathway to stimulate loss of muscle mass. Cell Metab. 2013; 18(3):368-79. Epub 2013/09/ 10. doi: 10.1016/j.cmet.2013.07.012 PMID: 24011072; PubMed Central PMCID: PMC3794464. 
23. Macdonald JH, Marcora SM, Jibani MM, Kumwenda MJ, Ahmed W, Lemmey AB. Nandrolone decanoate as anabolic therapy in chronic kidney disease: a randomized phase II dose-finding study. Nephron Clinical practice. 2007; 106(3):c125-35. Epub 2007/05/25. doi: 10.1159/000103000 PMID: 17522475.

24. Butterfield GE, Thompson J, Rennie MJ, Marcus R, Hintz RL, Hoffman AR. Effect of rhGH and rhIGF-I treatment on protein utilization in elderly women. Am J Physiol. 1997; 272(1 Pt 1):E94-9. Epub 1997/ 01/01. PMID: 9038857.

25. Cohn RD, van Erp C, Habashi JP, Soleimani AA, Klein EC, Lisi MT, et al. Angiotensin II type 1 receptor blockade attenuates TGF-beta-induced failure of muscle regeneration in multiple myopathic states. Nat Med. 2007; 13(2):204-10. Epub 2007/01/24. doi: 10.1038/nm1536 PMID: 17237794; PubMed Central PMCID: PMC3138130.

26. Caron AZ, Haroun S, Leblanc E, Trensz F, Guindi C, Amrani A, et al. The proteasome inhibitor MG132 reduces immobilization-induced skeletal muscle atrophy in mice. BMC Musculoskelet Disord. 2011; 12:185. Epub 2011/08/17. doi: 10.1186/1471-2474-12-185 PMID: 21843349; PubMed Central PMCID: PMC3173404.

27. Jamart C, Raymackers JM, Li An G, Deldicque L, Francaux M. Prevention of muscle disuse atrophy by MG132 proteasome inhibitor. Muscle Nerve. 2011; 43(5):708-16. Epub 2011/04/05. doi: 10.1002/mus. 21949 PMID: 21462205.

28. Eddins MJ, Marblestone JG, Suresh Kumar KG, Leach CA, Sterner DE, Mattern MR, et al. Targeting the ubiquitin E3 ligase MuRF1 to inhibit muscle atrophy. Cell Biochem Biophys. 2011; 60(1-2):113-8. Epub 2011/03/31. doi: 10.1007/s12013-011-9175-7 PMID: 21448668.

29. Cirak S, Arechavala-Gomeza V, Guglieri M, Feng L, Torelli S, Anthony K, et al. Exon skipping and dystrophin restoration in patients with Duchenne muscular dystrophy after systemic phosphorodiamidate morpholino oligomer treatment: an open-label, phase 2, dose-escalation study. Lancet. 2011; 378 (9791):595-605. Epub 2011/07/26. doi: 10.1016/S0140-6736(11)60756-3 PMID: 21784508; PubMed Central PMCID: PMC3156980.

30. Chen Y, Sood S, Biada J, Roth R, Rabkin R. Increased workload fully activates the blunted IRS-1/PI3kinase/Akt signaling pathway in atrophied uremic muscle. Kidney Int. 2008; 73(7):848-55. Epub 2008/ 01/25. 5002801 [pii] doi: 10.1038/sj.ki.5002801 PMID: 18216779.

31. Majchrzak KM, Pupim LB, Flakoll PJ, Ikizler TA. Resistance exercise augments the acute anabolic effects of intradialytic oral nutritional supplementation. Nephrol Dial Transplant. 2008; 23(4):1362-9. Epub 2007/12/11. gfm773 [pii] doi: 10.1093/ndt/gfm773 PMID: 18065829.

32. Kopple JD, Wang H, Casaburi R, Fournier M, Lewis MI, Taylor W, et al. Exercise in maintenance hemodialysis patients induces transcriptional changes in genes favoring anabolic muscle. J Am Soc Nephrol. 2007; 18(11):2975-86. Epub 2007/10/19. doi: 10.1681/ASN.2006070794 PMID: 17942969.

33. Conference NC. NIH Consensus Conference. Acupuncture. Jama. 1998; 280(17):1518-24. Epub 1998/11/11. PMID: 9809733.

34. Ernst $\mathrm{G}$, Strzyz H, Hagmeister $\mathrm{H}$. Incidence of adverse effects during acupuncture therapy-a multicentre survey. Complementary therapies in medicine. 2003; 11(2):93-7. Epub 2003/06/13. PMID: 12801494

35. MacPherson $\mathrm{H}$, Thomas $\mathrm{K}$, Walters $\mathrm{S}$, Fitter $\mathrm{M}$. The York acupuncture safety study: prospective survey of 34000 treatments by traditional acupuncturists. BMJ. 2001; 323(7311):486-7. Epub 2001/09/05. PMID: 11532841; PubMed Central PMCID: PMC48134.

36. Onda A, Jiao Q, Nagano Y, Akimoto T, Miyamoto T, Minamisawa S, et al. Acupuncture ameliorated skeletal muscle atrophy induced by hindlimb suspension in mice. Biochem Biophys Res Commun. 2011; 410(3):434-9. Epub 2011/06/16. doi: 10.1016/j.bbrc.2011.05.152 PMID: 21672518.

37. Takaoka Y, Ohta M, Ito A, Takamatsu K, Sugano A, Funakoshi K, et al. Electroacupuncture suppresses myostatin gene expression: cell proliferative reaction in mouse skeletal muscle. Physiol Genomics. 2007; 30(2):102-10. Epub 2007/03/08. doi: 10.1152/physiolgenomics.00057.2006 PMID: 17341691.

38. Grefte S, Kuijpers-Jagtman AM, Torensma R, Von den Hoff JW. Skeletal muscle development and regeneration. Stem cells and development. 2007; 16(5):857-68. Epub 2007/11/15. doi: 10.1089/scd. 2007.0058 PMID: 17999606.

39. Wang XH. MicroRNA in myogenesis and muscle atrophy. Curr Opin Clin Nutr Metab Care. 2013; 16 (3):258-66. Epub 2013/03/02. PMID: 23449000.

40. Nakasa $T$, Ishikawa $M$, Shi M, Shibuya $H$, Adachi N, Ochi M. Acceleration of muscle regeneration by local injection of muscle-specific microRNAs in rat skeletal muscle injury model. J Cell Mol Med. 2010; 14(10):2495-505. Epub 2009/09/17. doi: 10.1111/j.1582-4934.2009.00898.x PMID: 19754672.

41. Goljanek-Whysall K, Pais H, Rathjen T, Sweetman D, Dalmay T, Munsterberg A. Regulation of multiple target genes by miR-1 and miR-206 is pivotal for C2C12 myoblast differentiation. J Cell Sci. 2012; 125 (Pt 15):3590-600. Epub 2012/05/19. doi: 10.1242/jcs.101758 PMID: 22595520. 
42. Gagan J, Dey BK, Layer R, Yan Z, Dutta A. Notch3 and Mef2c proteins are mutually antagonistic via Mkp1 protein and miR-1/206 microRNAs in differentiating myoblasts. J Biol Chem. 2012; 287

(48):40360-70. Epub 2012/10/12. doi: 10.1074/jbc.M112.378414 PMID: 23055528; PubMed Central PMCID: PMC3504751.

43. Liu N, Williams AH, Maxeiner JM, Bezprozvannaya S, Shelton JM, Richardson JA, et al. microRNA206 promotes skeletal muscle regeneration and delays progression of Duchenne muscular dystrophy in mice. J Clin Invest. 2012; 122(6):2054-65. Epub 2012/05/02. doi: 10.1172/JCI62656 PMID: 22546853; PubMed Central PMCID: PMC3366415.

44. Man KM, Man SS, Shen JL, Law KS, Chen SL, Liaw WJ, et al. Transcutaneous electrical nerve stimulation on ST36 and SP6 acupoints prevents hyperglycaemic response during anaesthesia: a randomised controlled trial. European journal of anaesthesiology. 2011; 28(6):420-6. Epub 2010/10/22. PMID: 20962656.

45. Lin RT, Tzeng CY, Lee YC, Chen YI, Hsu TH, Lin JG, et al. Acupoint-specific, frequency-dependent, and improved insulin sensitivity hypoglycemic effect of electroacupuncture applied to drug-combined therapy studied by a randomized control clinical trial. Evidence-based complementary and alternative medicine: eCAM. 2014; 2014:371475. Epub 2014/07/16. doi: 10.1155/2014/371475 PMID: 25024728; PubMed Central PMCID: PMC4082841.

46. NIH Consensus Conference. Acupuncture. Jama. 1998; 280(17):1518-24. Epub 1998/11/11. 9809733.

47. Hua Y, Zhang Y, Ren J. IGF-1 deficiency resists cardiac hypertrophy and myocardial contractile dysfunction: role of microRNA-1 and microRNA-133a. J Cell Mol Med. 2012; 16(1):83-95. Epub 2011/03/ 23. doi: 10.1111/j.1582-4934.2011.01307.x PMID: 21418519. 